\title{
Effect of a herbal yeast food supplement and long-distance running on immunological parameters
}

\author{
F.K. Gmünder PhD1, P.W. Joller PhD ${ }^{2}$, H.I. Joller-Jemelka $\mathrm{MD}^{3}$, B. Bechler BS ${ }^{1}$, M. Cogoli \\ $\mathrm{PhD}^{1}$, W.H. Ziegler MD ${ }^{4}$, J. Müller MD ${ }^{4}$, R.E. Aeppli $\mathrm{MD}^{2}$ and A. Cogoli PhD ${ }^{1}$ \\ ${ }^{1}$ Institute of Biotechnology, Swiss Federal Institute of Technology, Zurich, Switzerland \\ 2 ANAWA Laboratories, Wangen, Switzerland \\ ${ }^{3}$ Department of Clinical Immunology, University Hospital, Zurich, Switzerland \\ ${ }^{4}$ Department of Internal Medicine, University Hospital, Zurich, Switzerland
}

The effect of a food supplement on immunological parameters of 16 long-distance runners was tested in a randomized, double-blind and placebo-controlled trial. The supplement comprised plasmolysed herbal yeast, malt, honey, and orange juice. No statistically significant differences between the two groups regarding the following variables were detected at three sessions at rest and immediately after a $21 \mathrm{~km}$ run: total and differential white blood cell counts, numbers of $B$ - and T-cells and Tsubpopulations, concanavalin-A-induced lymphocyte proliferation, serum levels of immunoglobulins, neopterin, IL-2 receptors, $\beta_{2}$-microglobulin, complement factor b, c4 and c3c, and c1-inactivator. These findings suggest that the effects of the tested food supplement on these parameters are negligible with respect to improvements in the immunological status of long-distance runners. The changes observed immediately after the run had a transient character. In both groups, however, low lymphocyte counts, IgG subclass 2 levels and c1-inactivator levels were noted at rest, which indicate that the immune status of endurance athletes may be affected by training.

Keywords: Physical stress, humoral immunity, cellular immunity, food supplement

\section{Introduction}

Nutrition has been recognized as playing a role in physical performance of man. In particular it has been suggested that an adequate vitamin and mineral supply is needed to cover the extra demands of the exercising body ${ }^{1,2}$. However, it is doubtful whether athletes need extra vitamin and mineral supplements if a well-balanced diet is guaranteed ${ }^{3-5}$. At best only minute improvements of the physical performance have been reported in well-controlled studies, except

Address for correspondence: Felix K. Gmünder, PhD, Institute of Biotechnology, Space Biology Group, ETH-Hönggerberg/HPT, CH-8093 Zurich, Switzerland

(C) 1990 Butterworth-Heinemann Ltd 0306-4179/90/020103-10 in cases of vitamin or mineral deficiency ${ }^{4,6,7}$. Nevertheless, many coaches and medical advisers recommend the daily intake of vitamin and mineral supplements ${ }^{5,8}$. It is estimated that $30-80$ per cent of athletes regularly take supplements of one form or another ${ }^{5,8}$.

Excessive intake of synthetic vitamin supplements may have detrimental effects on health, 10 . Consequently many athletes prefer so-called natural supplements such as honey, royal jelly, bee pollen, and various forms of complex yeast preparations. Although these products contain less vitamins and minerals than the synthetic supplements, the makers suggest that they are in a biologically more active form. Furthermore, the makers of the 'natural-wayproducts' claim that their supplements contain, beside vitamins and minerals in natural form, 'complex' compounds that have not yet been identified chemically. The manufacturers underline that precisely these components protect the stressed athlete from infections and wear, and even enhance his or her physical performance. It is thought that malnutrition can interfere with the immune defence system. However, nutritional deficiencies are difficult to define and the precise mechanisms are not known ${ }^{4,11,12}$. In particular no scientific evidence is available to support the claims of the manufacturers of natural vitamin and mineral supplements. Nevertheless, these products are widely used by leisure sportsmen, fitness freaks, and top competitive athletes, which highlights the needs for a scientific investigation into this issue.

In mice, dietary nucleotide restriction leads to a marked decrease in cell-mediated immunity ${ }^{13}$. In rodents that were fed with Bio-Strath ${ }^{\circledR *}$, a complex yeast preparation rich in nucleotides, the growth rate was substantially increased ${ }^{14}$, survival time after a lethal infection was significantly prolonged, and the proportion of surviving animals was markedly higher as compared to controls $s^{15,16}$. This was explained by an increase in the number of immunocompetent cells in the animals receiving the food supplement ${ }^{15}$.

* Bio-Strath ${ }^{\circledast}$ Elixir/Aufbaumittel 
In athletes the immune status is transiently affected by short- and long-term exercise ${ }^{17,18}$. In particular, peripheral counts of leukocytes, lymphocytes and their subpopulations, and the mitogenic response of lymphocytes to concanavalin $\mathrm{A}$ (con $\mathrm{A}$ ) have been shown to be affected by runs of one to three hours duration ${ }^{19-22}$. In blood samples of resting athletes abnormally low lymphocyte counts and low levels of IgG were noted 17,23 . It was suggested that the reduced immunity in endurance athletes may be due to the prolonged physical stress of daily endurance work-outs ${ }^{24,25}$. In relation to stress and immunity it has been proposed that the activity of the sympathoadrenal system and psychological factors play a contributing role in modulating the immune response ${ }^{26,27}$. Therefore, we have chosen immunological variables as a means to determine whether a widely used food supplement based on plasmolysed herbal yeast, malt, honey, and orange juice (BioStrath $\left.{ }^{\circledR}\right)$ affects immunity in trained long-distance runners.

The immune status was firstly monitored at rest before the runners received the supplement and the placebo. The progress of the immune status at rest was recorded in a blood draw that was made after a 27-day regimen. This set-up should reveal if the immune status was influenced at rest. Secondly, blood was drawn immediately after a $21 \mathrm{~km}$ run and two days after the run at rest. This set-up should reveal if the food supplement exerted an effect on the individual capability to restore homeostasis following a deviation from the baseline values due to the physical stress.

\section{Methods}

Test subjects and design of the study

Three female and 13 male runners served as test subjects for this study. They were randomly assigned (double-blind) to receive either the food supplement (one female, seven male) or a placebo (two female, six male). No significant differences were found between the two groups regarding age, height, weight, compliance, and training intensity before and during the study (Table 1). Informed consent was obtained from the volunteers.

\section{Food supplement}

The food supplement comprised plasmolysed herbal yeast, malt, honey, and orange juice (Bio-Strath $\left.{ }^{\circledR}\right)$. The placebo was made up of sucrose and caramel. The intake of the food supplement began at day 1 and ended at day 31 . The regimen was $3 \times 10 \mathrm{ml}$ per day with a meal. The compliance was 87.1 per cent (median) in both groups (Table 1).

\section{Collection of blood samples}

Four blood samples were obtained: (i) a resting sample the day before the intake of the food supplement began (day 0), (ii) a resting sample after a supplement regimen of 27 days duration, (iii) a sample taken two to five minutes after the subjects finished a $21 \mathrm{~km}$ run (day 29), and (iv) a resting sample two days after the run (day 31). The first blood draw prior to the administration of the food supplement and the placebo should help to decide whether the two groups differed in regard to the immunological variables tested. Venipuncture was performed from 1245 to 1300 hours and from 0945 to 1015 hours, for the resting samples and after the run, respectively. The athletes were seated for $\mathbf{3 0}$ minutes under low-arousing conditions before the resting blood samples were drawn. The blood was collected in Heparin-Vacutainers, immediately cooled on ice, and centrifuged in the cold at $3500 \mathrm{~g}$ for 20 minutes. The heparinized plasma was immediately frozen and stored at $-70^{\circ} \mathrm{C}$ until ready for analysis (within four weeks). Lymphocyte purification and tests were performed one to two hours after drawing blood. Assessments of plasma proteins and metabolites were made within six hours.

Table 1. Comparison of anthropometric data, training intensities, and compliance

\begin{tabular}{|c|c|c|c|c|c|c|}
\hline \multirow[t]{2}{*}{ Variable } & \multicolumn{3}{|c|}{ Test group } & \multicolumn{3}{|c|}{ Control group } \\
\hline & 25 th & Median & 75th & 25th & Median & 75th \\
\hline \multirow[t]{2}{*}{ Age (years) } & \multicolumn{3}{|c|}{28.0} & \multicolumn{3}{|c|}{33.0} \\
\hline & 24.0 & & 37.0 & 27.5 & & 36.0 \\
\hline \multirow[t]{2}{*}{ Height (cm) } & \multicolumn{3}{|c|}{178.5} & \multicolumn{3}{|c|}{177.0} \\
\hline & 175.0 & & 183.5 & 169.0 & & 183.0 \\
\hline Weight (kg) & \multicolumn{3}{|c|}{67.0} & \multicolumn{3}{|c|}{64.5} \\
\hline $\begin{array}{l}\text { Training intensity } \\
\text { during study }(\mathrm{km} / \mathrm{m})\end{array}$ & \multicolumn{2}{|r|}{195.0} & 225.5 & \multicolumn{3}{|c|}{155.0} \\
\hline $\begin{array}{l}\text { Training intensity } \\
\text { before study }(\mathrm{km} / \mathrm{m})\end{array}$ & 144.5 & 165.0 & 230.0 & 110.0 & 165.0 & 230.0 \\
\hline \multirow[t]{2}{*}{ Compliance (\%) } & \multicolumn{3}{|c|}{87.1} & \multicolumn{3}{|c|}{87.1} \\
\hline & 72.6 & & 96.8 & 79.0 & & 93.5 \\
\hline
\end{tabular}

The data printed in boldface are medians. Below the medians the 25 th and 75 th percentiles are listed. The two groups do not differ significantly (Kolmogorov-Smirnov and U test). 
Determination of white blood cell number

White blood cell (WBC) counts were determined with a haematology analyzer (Hemalog-1, Technicon, Tarrytown, New York, USA).

\section{Identification of lymphocyte subsets}

After purification of lymphocytes using FicollHypaque density gradient centrifugation and labelling with fluorescent monoclonal antibodies (Leu 2, Leu 3, Leu 4, Leu 11, Leu 12, and anti HLA-DR; Becton Dickinson, Mountain View, California, USA) lymphocyte subsets were identified on a fluorescence-activated cell system (FACS, Becton Dickinson). The spectra of the immunofluorescent-labelled cells and cell numbers were recorded within the lymphocyte cluster following the instructions of the manufacturer (Becton Dickinson).

\section{Assessment of lymphocyte responsiveness}

Lymphocyte activation by con A was performed in whole-blood cultures obtained by diluting fresh blood (1:10) with culture medium as described by Lorenzi et al. ${ }^{28}$. This simplified in vitro lymphocyte activation procedure has been developed in our laboratory for in-flight tests of spacelab astronauts. Results are expressed as the relative proliferation index (RPI). The use of this procedure assists comparisons between serial tests ${ }^{20}$.

\section{Immunoglobulins, immunoglobulin $G$ subclasses, $\beta_{2}$ - microglobulin, IL-2 receptors, neopterin, and plasma proteins}

These variables were assessed with routine methods in a clinical immunology laboratory. The methods have been described in detail by Wüthrich et al. ${ }^{29}$.

\section{Determination of stress-associated hormones}

Blood levels of cortisol were determined using a radioimmunoassay kit (Cortisol Bridge Kit, Serono Diagnostic S.A., Chavannes-de-Bogis, Switzerland) according to the instructions of the manufacturer. Adrenaline and noradrenaline were measured with the highly sensitive enzymatic radioisotope method of Da Prada and Zürcher ${ }^{30}$.

\section{Statistical analysis}

To provide information about the effect of the supplement, the values of the test and the control group were compared using non-parametric test techniques for non-matched samples. The Kolmogorov-Smirnov test (2-tailed) checks for differences in the median and homogeneity of all sort, whereas the Wilcoxon-Mann-Whitney U-test (2-tailed) is more powerful in detecting differences in the medians. To test changes within one group, the Wilcoxon signedrank test for paired samples (2-tailed) was used. A $P$ level of $\leqslant 0.05$ was considered to be statistically significant.

\section{Results}

No significant differences of humoral and cellular immunological parameters between the two groups were detected either in the blood draw before the athletes received the food supplement or in the three blood draws after a regimen of 27-31 days. The tested parameters are depicted in Figures 1 and 2.

The levels of the stress-associated hormones (adrenaline, noradrenaline and cortisol) were included to check the impact of the activity of the sympatho-adrenalin axis and corticosteroid responses on the immune system. This should help to decide whether the two groups experienced the same stress at the blood draws, in particular that following the run. As shown in Figure 1, no significant differences were found in the levels of stressassociated hormones between the two groups.

A $21 \mathrm{~km}$ run (duration 1:15-1:50 hr under difficult conditions (snow-covered tracks)) was used to challenge the homeostasis of the immune system. Thus the analysis of how effectively homeostasis was restored at day 31 was selected to decide which group could cope better with the deviation. The test group recovered significantly better regarding the exerciseinduced increase of natural killer and suppressor/ cytotoxic cells, the reduced lymphocyte responsiveness to con $A$, the increase of IgG subclass 1 , and the decrease of IgG subclass 2 (Table 2). By contrast, the control group recovered significantly better in the matter of levels of neopterin and $\beta_{2}$-microglobulin. No difference between the two groups was found during recovery with respect to the number of leukocytes, lymphocytes, and levels of IgG. It is worth mentioning that despite the statistically significant differences regarding restoration of homeostasis with the Wilcoxon signed-rank test, they are small on an absolute scale (Figures 1 and 2).

We noticed that some of the tested variables in the majority of the 16 test subjects were remarkably close to the lower limits of the reference or normal range in all resting blood samples. In addition, some parameters were transiently affected by the run. To provide information for this type of analysis the data of the two groups were combined. The sample size of 16 subjects permits a more pronounced picture. This procedure is duly justified since the differences between the two groups are, although statistically detectable, minute on an absolute scale, and therefore negligible.

Table 2. Statistical analysis of the individual changes following the run

\begin{tabular}{lcc}
\hline Parameter & Test group & Control group \\
\hline Leukocyte counts & $* * *$ & $* * *$ \\
Lymphocyte counts & n.s. & n.s. \\
Suppressor cells & $*$ & n.s. \\
Natural killer cells & $* * *$ & $* *$ \\
Mitogenic response & $* * *$ & $*$ \\
IgG & $*$ & n.s. \\
IgG subclass 1 & $* * *$ & n.s. \\
IgG subclass 2 & $* * *$ & $* * *$ \\
B2-microglobulin & n.s. & $* *$ \\
Neopterin & n.s. &
\end{tabular}

The data of the blood draw immediately after the run were compared to those at rest after 2 days recovery. The Wilcoxon signed rank test for matched samples (2-tailed) was used. n.s., not significant; ${ }^{*} P \leqslant 0.05,{ }^{* *} P \leqslant 0.025,{ }^{* * *} P \leqslant 0.01$ 

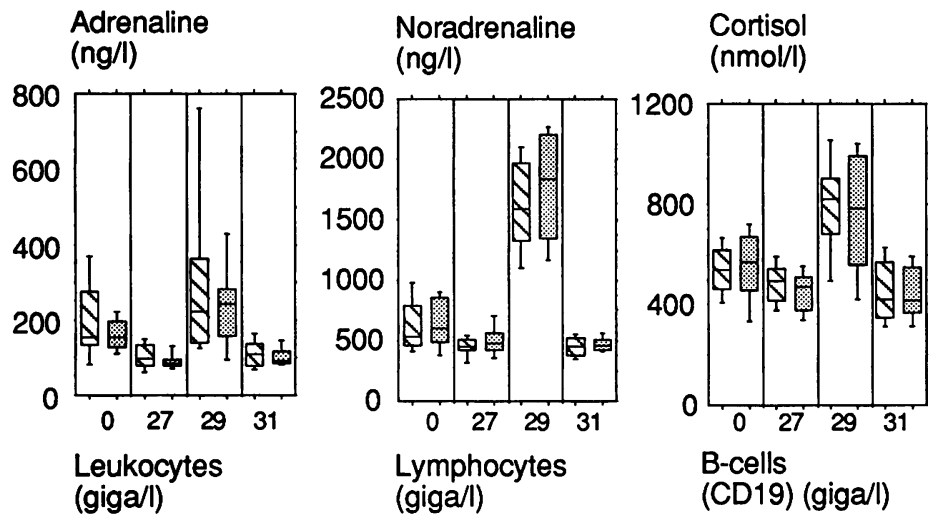

Con A response

(RPI)
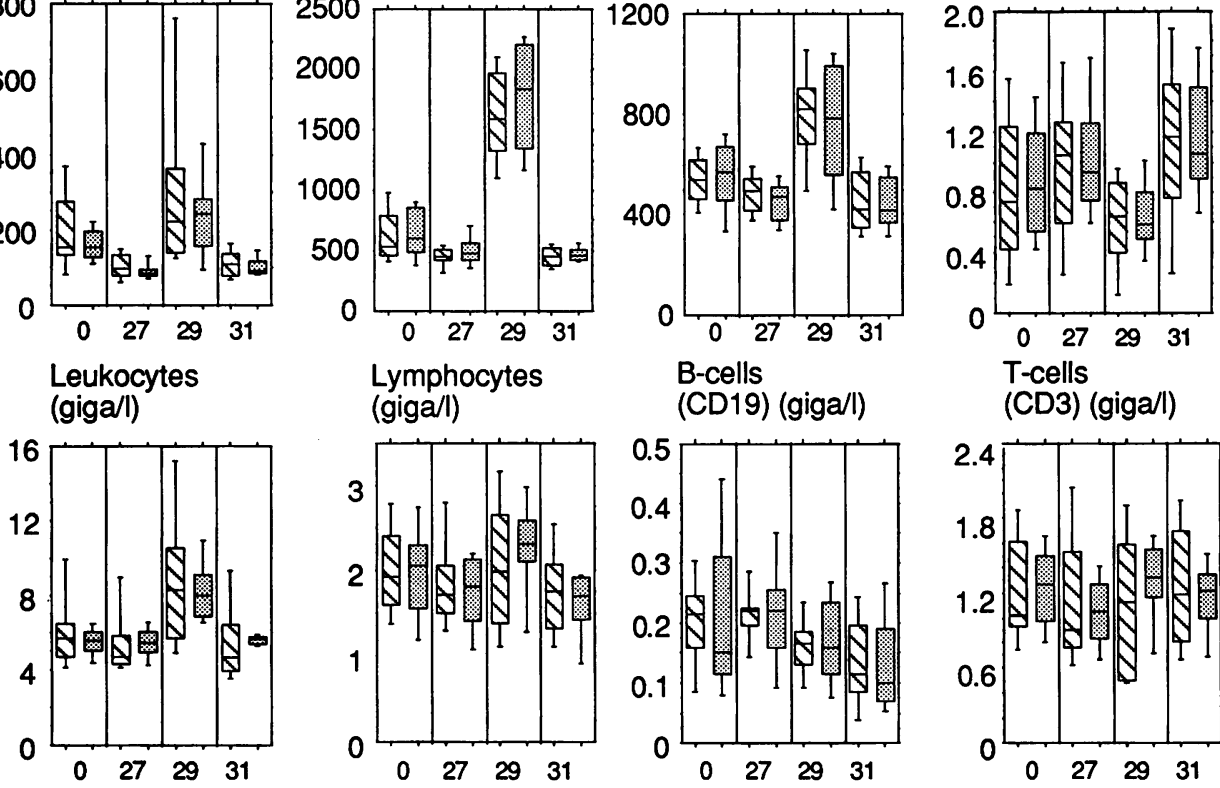

Helper cells (CD4) (giga/l)

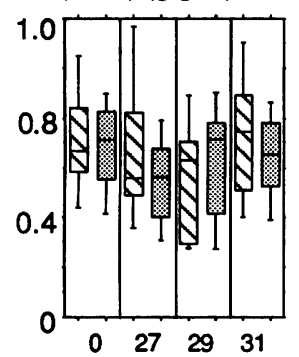

Suppressor cells (CD8) (giga/l)

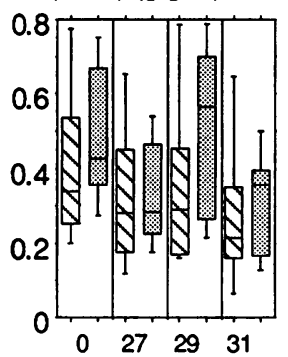

NK cells (CD16) (giga/l)
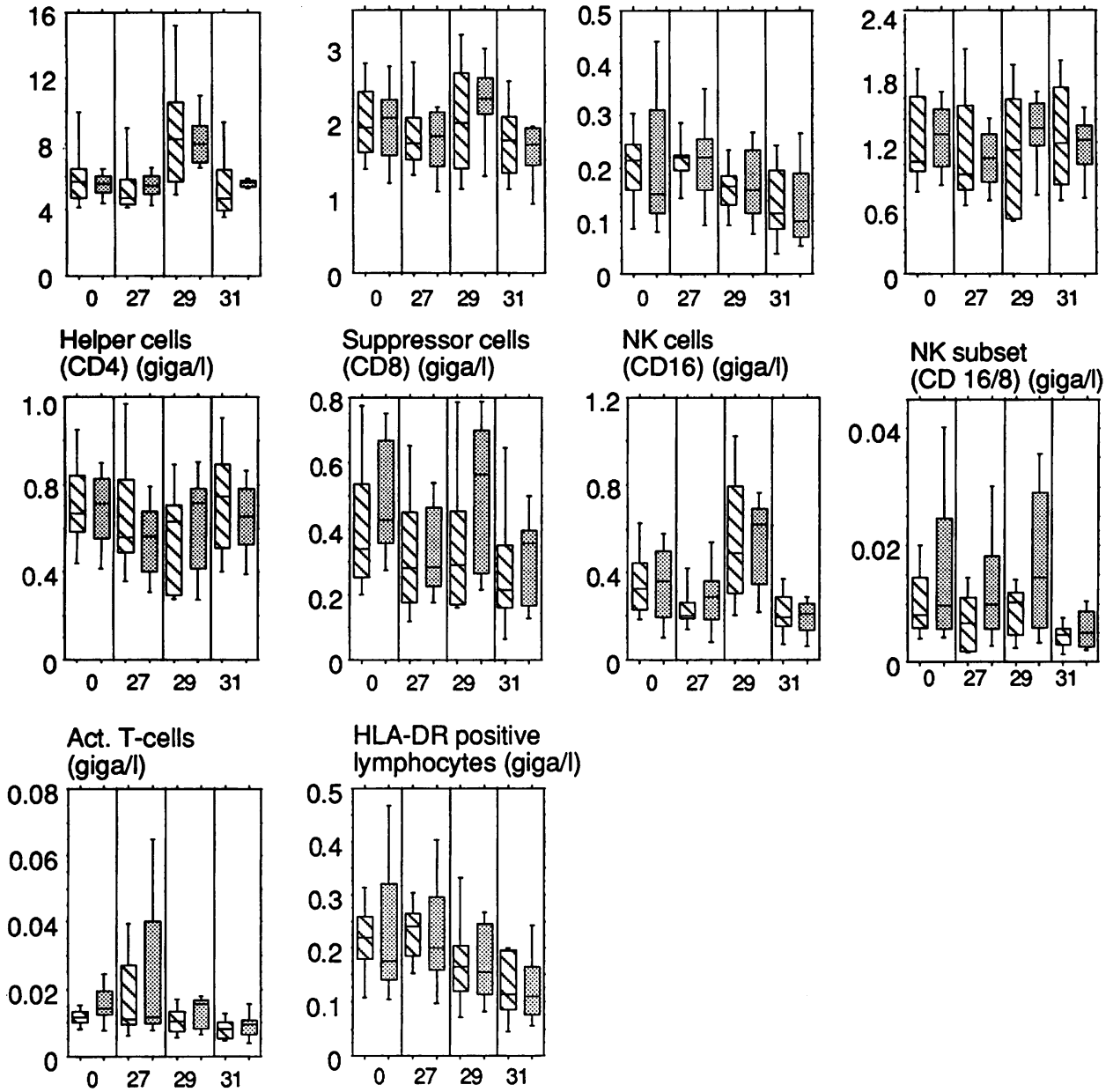

Figure 1. Box plot representation of the effect of a food supplement based on a complex yeast preparation and running on stress-associated hormones and cellular immunological variables. The athletes received a placebo (hatched boxes) or a complex yeast preparation (grey boxes). The box plots include bottom T-bar, bottom box limit, bar in box, top box limit, and top T-bar which represent the 10th, 25th, 50th, 75th, and 90th percentile respectively. The numbers on the abscissa are a resting sample at day 0 (before the athletes received the food supplement and the placebo), a resting sample at day 27 , a sample immediately after the run (day 29), and a resting sample at day 31 . The values of the test group never differ significantly from the control group

The analysis of the resting samples (day 0,27 and 31; Table 3) reveal that lymphocyte counts and levels of IgG subclass 2 and c-1-inactivator were depressed as compared to the normal range (Table 4). The median of lymphocyte counts $(n=16)$ was equal or below 2 giga/1 and the 25th percentile was found to be at the lower normal range. B- and T-cell counts and the helper/ inducer and suppressor/cytotoxic subsets contributed altogether to the low total lymphocyte counts, as shown in Table 3. Whereas the IgG levels appeared only slightly depressed in most test subjects, we observed strikingly low levels of the proportion of IgG subclass 2 . The 25th percentile was always below the normal range at rest (Table 3). The medians of $\mathrm{c}-1$ inactivator levels were also close to the lower margin in all four blood specimens (Tables 3 and 4). 
Herbal yeast food, long-distance running and immunological parameters: F.K. Gmünder et al.
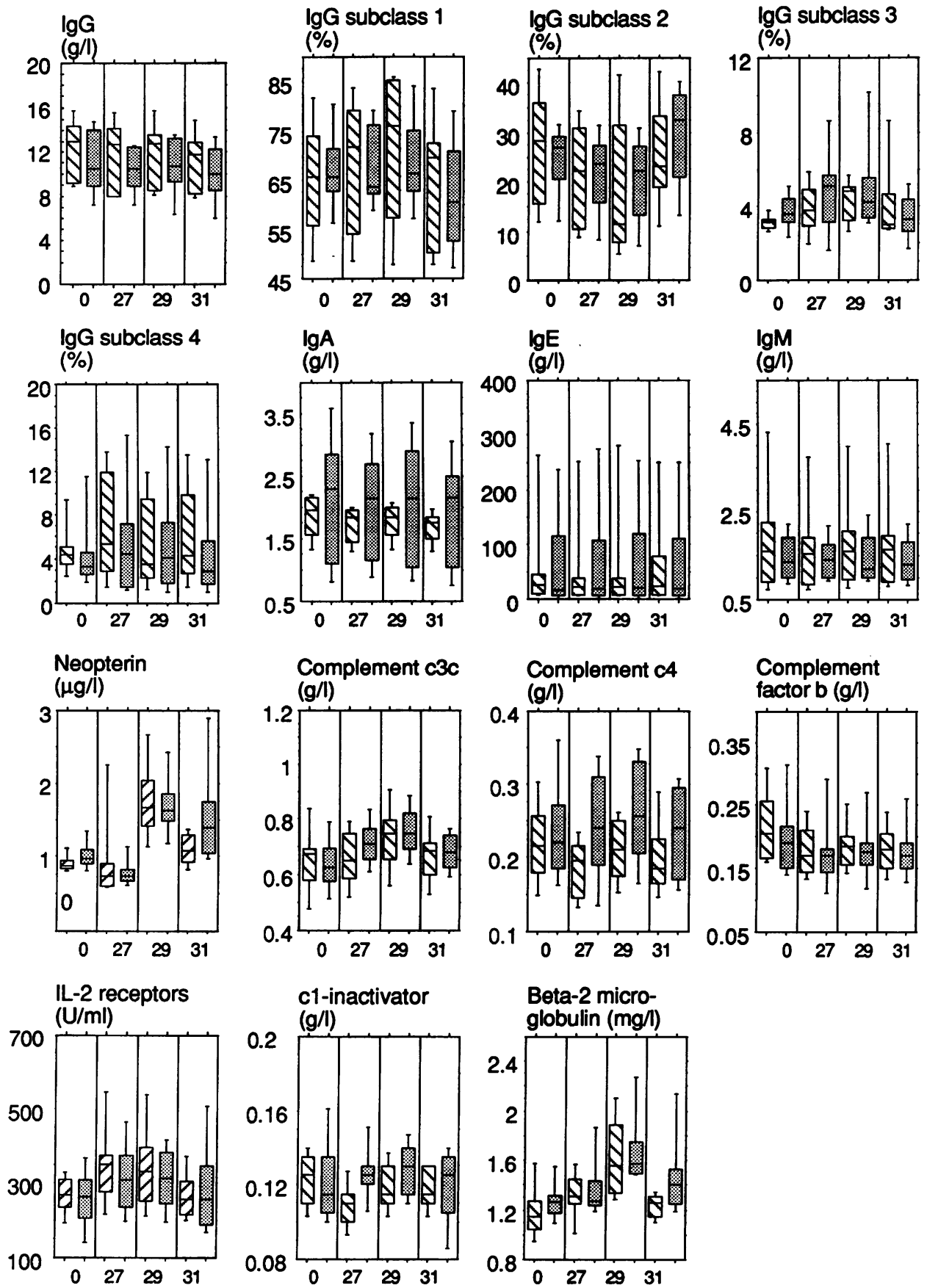

Figure 2. Box plot representation of the effect of a food supplement based on a comlex yeast preparation and running on humoral immunological variables. For further explanations consult caption of Figure 1. The values of test group never differ significantly from the control group

Immediately after the run, cellular and humoral parameters were transiently affected. An explanation for an increase in cell counts and soluble plasma constituents is that the plasma volume decreases due to fluid loss by transpiration and perspiration. A decrease of plasma volume is reflected by an increase of the haematocrit. However, under standard environmental conditions the haematocrit in trained male athletes is only increased by a few percent on completion of a marathon ${ }^{31}$. Whereas leukocyte and natural killer counts increased significantly, the numbers of lymphocytes and lymphocyte respon- siveness decreased (Table 3). It is interesting that although the number of B-cells decreased immediately after the run as compared to the number before the exercise, the values did not return to the baseline (Table 3). Similarly, we noted that the numbers of HLA-DR-positive lymphocytes, suppressor/ cytotoxic, and activated T-cells did not change immediately after the run, but were decreased two days later (Table 3 ). The statistical analysis of humoral parameter values indicates a similar behaviour regarding the decrease of IgG levels following the run. Levels of neopterin, $\beta_{2}$-microglobulin and 
Herbal yeast food, long-distance running and immunological parameters: F.K. Gmünder et al.

Table 3. Effect of a $21 \mathrm{~km}$ run on cellular and humoral variables

\begin{tabular}{|c|c|c|c|c|c|c|c|c|c|c|c|c|c|c|}
\hline \multirow{2}{*}{ Cellular variables } & \multicolumn{3}{|c|}{ Day 0 (rest) } & \multicolumn{3}{|c|}{ Day 27 (rest) } & & \multicolumn{3}{|c|}{ Day 29 (run) } & & \multicolumn{3}{|c|}{ Day 31 (rest) } \\
\hline & & & & & & & & & & & & & & \\
\hline Leukocyte counts & 4.9 & 5.6 & 6.1 & 4.6 & 5.2 & 6.1 & *** & 6.5 & 8.0 & 10.0 & $* * *$ & 4.7 & 5.5 & 5.9 \\
\hline Lymphocyte counts & 1.6 & 2.0 & 2.3 & 1.5 & 1.8 & 2.1 & $*$ & 1.5 & 1.3 & 2.7 & $*$ & 1.4 & 1.7 & 1.9 \\
\hline B-cells (CD19) & 0.12 & 0.19 & 0.25 & 0.17 & 0.22 & 0.24 & $* *$ & 0.13 & 0.17 & 0.22 & $*$ & 0.08 & 0.1 & 0.2 \\
\hline $\begin{array}{l}\text { T-cells (CD3) } \\
\text { Helper/inducer }\end{array}$ & 0.92 & $\begin{array}{l}1.12 \\
0.69\end{array}$ & 1.5 & 0.77 & $\begin{array}{l}0.97 \\
0.56\end{array}$ & 1.37 & & 0.75 & $\begin{array}{l}1.29 \\
0.7\end{array}$ & 1.55 & & 0.9 & $\begin{array}{r}1.18 \\
0.7\end{array}$ & 1.48 \\
\hline (CD4) & 0.58 & & 0.83 & 0.48 & & 0.7 & & 0.34 & & 0.75 & & 0.53 & & 0.81 \\
\hline $\begin{array}{l}\text { Suppressor/cytotoxic } \\
\text { (CD8) }\end{array}$ & 0.31 & 0.38 & 0.6 & 0.2 & 0.28 & 0.47 & & 0.22 & 0.32 & 0.63 & $*$ & 0.17 & 0.24 & 0.4 \\
\hline Natural killer (CD16) & 0.23 & 0.33 & 0.5 & 0.19 & 0.24 & 0.31 & ${ }^{* * *}$ & 0.32 & 0.56 & 0.73 & *** & 0.15 & 0.2 & 0.26 \\
\hline $\begin{array}{l}\text { Natural killer } \\
\text { (CD16/8) }\end{array}$ & 0.006 & 0.009 & 0.017 & 0.003 & 0.007 & 0.014 & & 0.005 & 0.01 & 0.018 & $* *$ & 0.003 & 0.005 & 0.007 \\
\hline $\begin{array}{l}\text { HLA-DR positive } \\
\text { lymphocytes }\end{array}$ & 0.14 & 0.2 & 0.26 & 0.17 & 0.22 & 0.28 & & 0.12 & 0.17 & 0.23 & $*$ & 0.08 & 0.12 & 0.19 \\
\hline Activated T-cells & 0.01 & 0.013 & 0.015 & 0.009 & 0.011 & 0.038 & & 0.008 & 0.012 & 0.016 & $*$ & 0.006 & 0.009 & 0.011 \\
\hline $\begin{array}{l}\text { Lymphocyte } \\
\text { response }\end{array}$ & 0.52 & 0.74 & 1.21 & 0.7 & 1.0 & 1.26 & ${ }^{* * *}$ & 0.49 & 0.61 & 0.86 & $* * *$ & 0.87 & 1.15 & 1.5 \\
\hline \multicolumn{15}{|l|}{ Humoral variables } \\
\hline Immunoglobulin A & 1.4 & 2.0 & 2.4 & 1.3 & 1.9 & 2.2 & & 1.4 & 1.9 & & & & 1.8 & \\
\hline Immunoglobulin E & 9.0 & 20.6 & 58.5 & 8.5 & 20.5 & $\begin{array}{r}2.2 \\
50.5\end{array}$ & & $\begin{array}{l}1.4 \\
7.5\end{array}$ & 22.0 & $\begin{array}{l}2.3 \\
52\end{array}$ & & $\begin{array}{l}1.3 \\
7.5\end{array}$ & 19.0 & $\begin{array}{r}2.5 \\
78.5\end{array}$ \\
\hline Immunoglobulin G & 9.1 & 12.1 & 14.1 & 8.1 & 11.6 & 12.9 & & 8.6 & 12.0 & 13.4 & *** & 8.1 & 10.9 & 12.8 \\
\hline IgG subclass 1 & 61 & 66 & 72 & 60 & 66 & 79 & & 63 & 69 & 83 & & 51 & 65 & 73 \\
\hline IgG subclass 2 & 17 & 27 & 31 & 11 & 24 & 29 & & 9 & 19 & 27 & $* *$ & 19 & 28 & 37 \\
\hline IgG subclass 3 & 2.9 & 3.3 & 3.8 & 3.0 & 4.1 & 5.7 & & 3.4 & 4.7 & 5.2 & & 2.8 & 3.1 & 4.5 \\
\hline IgG subclass 4 & 3.0 & 3.6 & 5.1 & 2.1 & 5.4 & 9.4 & & 2.2 & 3.5 & 8.7 & & 2.5 & 3.5 & 7.5 \\
\hline Immunoglobulin M & 1.0 & 1.5 & 2.0 & 1.0 & 1.5 & 1.9 & & 1.0 & 1.4 & 2.0 & & 1.0 & 1.5 & 1.9 \\
\hline Neopterin & 0.85 & 0.92 & 1.01 & 0.63 & 0.73 & 0.82 & $* * *$ & 1.49 & 1.66 & 1.86 & $*$ & 0.99 & 1.16 & 1.43 \\
\hline IL-2 receptors & 217 & 263 & 309 & 237 & 336 & 373 & & 251 & 313 & 397 & & 205 & 257 & 333 \\
\hline$\beta_{2}$-microglobulin & 1.1 & 1.2 & 1.3 & 1.2 & 1.3 & 1.4 & $* * *$ & 1.4 & 1.6 & 1.8 & $* *$ & 1.2 & 1.3 & 1.4 \\
\hline c1 inactivator & 0.11 & 0.12 & 0.14 & 0.11 & 0.12 & 0.13 & & 0.1 & 0.13 & 0.14 & & 0.1 & 0.12 & 0.13 \\
\hline Complement c3c & 0.58 & 0.66 & 0.69 & 0.63 & 0.69 & 0.76 & $* *$ & 0.68 & 0.75 & 0.8 & $* * *$ & 0.63 & 0.68 & 0.73 \\
\hline Complement c4 & 0.18 & 0.22 & 0.26 & 0.16 & 0.21 & 0.25 & & 0.2 & 0.22 & 0.28 & & 0.17 & 0.21 & 0.28 \\
\hline $\begin{array}{l}\text { Complement factor } b \\
(\mathrm{c}-3 \mathrm{PA})\end{array}$ & 0.16 & 0.2 & 0.24 & 0.15 & 0.17 & 0.18 & & 0.16 & 0.18 & 0.2 & & 0.15 & 0.18 & 0.2 \\
\hline
\end{tabular}

Blood was drawn at rest (day 0, 27 and 29) and immediately after the run (day 27). The data printed in boldface are medians. Below the medians the 25th and 75th percentiles are listed. The units are shown in Table 4. The Wilcoxon signed-rank test for matched samples was used for the statistical analysis of running induced changes. n.s., not significant; ${ }^{*} P \leq 0.05,{ }^{* *} P \leq 0.025,{ }^{* * *} P \leq 0.01$. 
Table 4. Normal ranges of the tested variables

\begin{tabular}{|c|c|c|c|}
\hline Parameter & Unit & Norma & al range \\
\hline $\begin{array}{l}\text { White blood cell counts } \\
\text { Lymphocytes } \\
\text { B-cells } \\
\text { T-cells } \\
\text { Helper/inducer } \\
\text { Suppressor/cytotoxic } \\
\text { IgA } \\
\text { IgE } \\
\text { IgM } \\
\text { IgG } \\
\text { IgG subclass } 1 \\
\text { IgG subclass } 2 \\
\text { IgG subclass } 3 \\
\text { IgG subclass } 4 \\
\text { Complement factor c3c } \\
\text { Complement factor c4 } \\
\text { Complement factor b } \\
\text { c1 inactivator } \\
\text { Neopterin } \\
\beta \text {-2-microglobulin } \\
\text { IL-2 receptors }\end{array}$ & $\begin{array}{l}\text { giga/l } \\
\text { giga/l } \\
\text { giga/l } \\
\text { giga/l } \\
\text { giga/l } \\
\text { giga/l } \\
\text { g/l } \\
\text { U/ml } \\
\text { g/l } \\
\text { g/l } \\
\% \\
\% \\
\% \\
\% \\
\text { g/l } \\
\text { g/l } \\
\text { g/l } \\
\text { g/l } \\
\mu g / l \\
\mathrm{mg} / \mathrm{l} \\
\mathrm{U} / \mathrm{ml}\end{array}$ & $\begin{array}{c}4.3-5 \\
1.5 \\
0.11- \\
0.73- \\
0.43- \\
0.23- \\
0.7-1 \\
10.0- \\
0.4- \\
7.0- \\
46.0- \\
19.5- \\
2.3- \\
2.5- \\
0.5 \\
0.14- \\
0.12- \\
0.1- \\
0 \\
0.01 \\
0\end{array}$ & $\begin{array}{lc}- & 10.0 \\
- & 4.0 \\
- & 0.63 \\
- & 2.3 \\
- & 1.5 \\
- & 0.88 \\
- & 4.4 \\
- & 180.0 \\
- & 2.6 \\
- & 19.0 \\
- & 67.0 \\
- & 39.5 \\
- & 8.3 \\
- & 5.9 \\
- & 1.2 \\
- & 0.45 \\
- & 0.4 \\
- & 0.3 \\
- & 2.5 \\
- & 2.4 \\
- & 477.0\end{array}$ \\
\hline
\end{tabular}

complement $\mathrm{c} 3 \mathrm{c}$ were significantly increased immediately after the run as compared to the resting sample 2 days prior to the run, and returned to baseline values 2 days after the run (Table 3 ).

\section{Discussion}

This study was originally designed to test the hypothesis presented by the manufacturer that a food supplement based on a complex yeast preparation might affect the immunological status of endurance athletes. In addition, we found that in both groups the levels of some cellular and humoral immunological parameters tended to be unusually low at rest as compared to the normal ranges. Moreover, we observed that physical exercise induced transient changes that have not been reported before. Therefore, the discussion is divided into two sections. Firstly we discuss the effect of the food supplement on the immune status of the runners. In the second section we discuss the impact of training and exercise on the immune status of runners observable in both groups.

The first major finding of this study is that no significant differences between the test group (taking the food supplement) and the control group (taking the placebo) were detected within the variables analysed (Figures 1 and 2). For statistical analysis of the two unmatched samples we used the Kolmogorov-Smirnov test and the $U$ test. The former is more powerful in detecting differences between the distribution functions and the latter is better suited to check for differences in the medians. The impact of the food supplement appears to be too small to make a difference between our two groups of eight athletes. It is important to note that both groups were equivalent regarding age, height, weight, compliance, and training intensities (Table 1). In addition, the two groups were similar with respect to the immunological status obtained before they received the food supplement and the placebo. However, when the ability of the two groups to restore homeostasis of affected variables after a deviation induced by a $21 \mathrm{~km}$ run was tested, we found significant, but on an absolute scale, small differences. The test group recovered significantly better with respect to leukocyte and lymphocyte counts, numbers of natural killer cells, and lymphocyte responsiveness. By contrast, the control group showed a more pronounced decrease of the neopterin and $\beta_{2}$-microglobulin blood levels after the run than did the test group. In relation to the deviation from homeostasis that was induced by the run, it is important that the stress experienced by the subjects was equivalent in both groups, as illustrated by the blood levels of the stress-associated hormones (adrenaline, noradrenaline and cortisol) at rest and immediately after the run. This is noteworthy, since it is thought that the response of stress-associated hormones to muscle exercise is an important factor in controlling the numbers of peripheral white blood cells and lymphocyte responsiveness ${ }^{19,20,32}$.

In mice it was found that a diet low in nucleotides compared with a normal diet depresses cell-mediated immunity ${ }^{13}$. The food supplement we used in this trial has been tested extensively in mice and rat studies. Fritz-Niggli ${ }^{33}$ found that mortality among highly irradiated mice $(500 \mathrm{R})$ was significantly reduced from 27.8 per cent (no supplement) to 11.1 per cent (with supplement). Michel and Fritz-Niggli34 showed that the food supplement helped to increase the fertility of mice after an irradiation with 25 and $50 \mathrm{R}$. It was concluded that the complex yeast preparation has radiation-protective abilities in mice. Ireson et al. ${ }^{35}$ transferred Ehrlich ascites tumours to mice to test whether the food supplement has tumour-protective abilities. They found that mice receiving the food supplement showed decreased tumour development as compared to control animals. The efficacy of the food supplement in rodents was further supported by the findings of Bagshaw and Leslie $^{14}$. They found that it was more efficient in supporting the growth rate of rats (determined as increase of body-weight over a period of 30 days after birth) than a synthetic vitamin preparation and a vitamin- and mineral-containing biscuit. The authors concluded from the vitamin and mineral analysis of the food that the increase of growth rate might be due to unknown growth factors that were not present in the standard diet or the synthetic vitamin and mineral supplements ${ }^{14}$. Leslie et al. ${ }^{16}$ and Joller ${ }^{15}$ tested the effect of the complex yeast preparation on the immunity of mice. Mice receiving either the food supplement or a placebo were injected intraperitoneally with Staphylococcus aureus. The animals that received the active preparation survived longer and showed a higher surviving rate than the controls. Joller ${ }^{15}$ went further by monitoring T-cell subpopulations in the spleen of mice receiving the food supplement and in controls. He found that numbers of T-helper/inducer cells were significantly increased in mice receiving the supplement as compared to those receiving a placebo. After injection of two-fold $\mathrm{LD}_{50}$ of Staphylococcus aureus those animals that were fed with the active supplement survived (all of 20) whereas most of the control animals died (seven of 
ten) ${ }^{15}$. It was suggested that the yeast preparation protected the mice from a lethal infection by mobilizing a greater number of immunocompetent spleen lymphocytes. These findings gave support to the idea that the immune status of humans might also be improved by this food supplement.

In human test subjects we were not able to detect such a beneficial effect. In particular we did not find an increase of T-cells or T-subpopulations in peripheral blood after administration of the food supplement as it was found in mice ${ }^{15}$. This discrepancy between the studies performed with murine and human test subjects may be explained (i) by a species difference regarding the response of the immune system to the complex yeast preparation, (ii) by the greater variability among human test subjects as compared to laboratory animals, (iii) by the possibility of vitamin and mineral limitations from the basic food in laboratory animals, and (iv) by differences of the effect of the food supplement on spleen lymphocytes as compared to peripheral blood lymphocytes. In addition, the set-up of this study did not include a challenge with an infectious agent as it was performed in animals. To circumvent this issue we selected a long-distance run as a challenge. A test using delayed type hypersensitivity (skin test) could possibly provide more information, since it is thought that this test mirrors the in vivo performance of $\mathrm{T}$-cell function in humans.

It must be admitted that in this trial the test panel mostly comprised athletes who neither belong to the national top level, nor comply with a very high intensity work-out plan (Table 1). This might have concealed the proposed immunity-enhancing effect of the food supplement, since it has been theorized that the immune system is only depressed after prolonged, regular and severe physical stress $^{17,24,25,36}$. In addition, one might argue that the size of the two samples (eight athletes in each group) was too small to detect the possibly minute effect on the immune status. However, this implies that the effects, if any, are clinically not relevant. We conclude that for athletes of medium performance as tested in this study, the effect of the food supplement based on plasmolysed herbal yeast can be neglected.

The second major finding of this study is that running workouts of a duration of two to six hours per week have an effect on cellular and humoral immunological variables at rest. For this type of analysis we joined the results of the two groups to obtain a more pronounced statement. The combination of the two groups is fully justified because only negligible differences between them were found.

It has been stated that the repeated stress of endurance training may have an adverse effect on the immune status in the long run ${ }^{18,23}$. Fitzgerald ${ }^{17}$ suggests that the sustained stress of daily vigorous workouts experienced by top endurance athletes may lead to a depressed immune status. Our results from medium-performance runners support this hypothesis. Previous studies reported on changes in immunological variables that were induced by a single bout of exercise $20,22,37-41$. By contrast, the effect of running training on the immune status of runners at rest has not been critically examined. This point could be of importance in understanding the suggested permanent impairment of the immune system in athletes. For the first time we monitored the progress of immunological parameters at rest in a period of more than four weeks.

The median of lymphocyte counts obtained at rest was at and below 2 giga/ 1 in the three blood draws obtained at rest. The 25 th percentile was almost identical with the lower limit of the normal range of $1.5 \mathrm{giga} / \mathrm{l}$ (Table 4). In a single blood draw at rest Green et al. ${ }^{23}$ found that 10 out of 20 marathon runners had lymphocyte counts below $1.5 \mathrm{giga} / 1$ at rest. Our results indicate that in resting runners the low lymphocyte counts are due to decreased numbers of B-cells, T-cells, helper/inducer cells, and suppressor/cytotoxic cells (Tables 3 and 4).

In this study we found that the percentage of IgG subclass 2 was abnormally low in most of the individuals. The 25th percentile is clearly below the lower margin of the reference range (Table 4). This IgG subclass is thought to interact with glycoproteins and lipopolysaccharides from Gram-negative bacterial cell walls. A decrease in the proportion of IgG subclass 2 is believed to be associated with an endotoxaemia. It is unlikely that the observed IgG subclass 2 depression is due to the five cases of colds and the diarrhoea that were observed during the study. In endurance athletes, however, the consumption of IgG subclass 2 may result from glycoproteins and lipopolysaccharides of Gram-negative gut bacteria and exposed to the immune system after impactinduced microlesions in the intestine endothelium. Bosenberg et al. ${ }^{37}$ and Brock-Utne et al. ${ }^{38}$ reported an increase of plasma endotoxin after a triathlon and a running event respectively. This increase in lipopolysaccharides was accompanied by a decrease of related IgG. The decreased IgG subclass 2 levels in the resting samples of this trial indicate that blood levels of endotoxins may be increased at rest even at training intensities of more than $100 \mathrm{~km}$ per month. C1-inactivator levels at rest were remarkably low and close to the lower normal limits (Tables 3 and 4) in the majority of test subjects. By contrast, complement factors $c 3 c, c 4$, and $b$ were normal throughout one month. This finding is in accordance with those of Green et al. ${ }^{23}$, who reported that complement c3 and c4 were normal in a single resting blood sample of marathon runners.

The changes in the cellular parameters induced by physical stress are in accord with earlier studies ${ }^{20,39-41}$, and return to baseline values within two days, with the only exception of B cells, HLA-DR-positive lymphocytes, suppressor/cytotoxic and activated Tcells. It appears that the changes in the numbers of these cell types was either delayed or persisted for hours and days after the run. This is consistent with earlier observations ${ }^{20}$.

Immunoglobulins have not been reported to be effected by acute exercise. In this study, however, a decrease of IgG subclass 2 was noted after the run. Again, this finding can be explained by the release of endotoxins from the gut after running ${ }^{37,38}$. For the first time we report about changes of neopterin, $\beta_{2}$-microglobulin, and complement c $3 c$ levels following long-term exercise (Table 4). The rise of the blood 
levels of neopterin is paramount. An increase of plasma neopterin levels may result from an enhanced metabolism of activated T-lymphocytes and macrophages. However, we are not able to explain how white blood cell activity or clearance of neopterin were affected during physical activity. An answer to this question may be given only after further analysis. The highly significant increase of plasma $\beta_{2^{-}}$ microglobulin levels found in this study confirms an earlier result of Ohno et al. ${ }^{42}$. They found a weakly significant increase in $\beta_{2}$-microglobulin after a short bout of exercise ( 30 minute bicycle ergometry). $\boldsymbol{\beta}_{2}$-microglobulin is a non-glycosylated peptide that is part of the class 1 histocompatibility antigen in the plasma membranes of B-cells. Free serum and urine levels are supposed to be elevated after B-cell activation. Again we do not have data that explain the changes in activity of B-cells or clearance of $\beta_{2}$-microglobulin. The present lack of data does not allow us to decide why complement $\mathrm{c} 3 \mathrm{c}$ was transiently increased after exercise, whereas the other constitutents of the complement cascade were not. Earlier studies on the effect of physical exercise on complement levels are contradictory. An increase of complement titres after a workload of 20 minute bicycle ergometry was reported by Eberhardt $t^{43}$. By contrast, no change of complement concentrations were observed after a $12 \mathrm{~km}$ run ${ }^{21}$.

Despite the marked exercise-induced transitory changes in the numbers of leukocytes and lymphocytes, subpopulation counts, and humoral variables, such single events are presumably not damaging ${ }^{17}$. In contrast, it is an open question if the observed changes in the resting samples of endurance athletes are hazardous and increase the liability to infections. In fact, coaches of national and international top athletes report that competitors are very often prone to infectious diseases such as colds and influenzatype ailments. Likewise, at the Olympic games in Seoul a strikingly high proportion of middle- and long-distance runners were subject to infectious diseases of the respiratory tract. By contrast, Green $e$ t al. ${ }^{23}$ found that nine of 20 marathon runners felt that running had increased, and one felt that it had decreased, his or her resistance to respiratory infections. Neverletheless, Fitzgerald ${ }^{17}$ and Neumann et al. ${ }^{36}$ hypothesize that the intensive training of elite endurance athletes may have detrimental effects on the immune system. This underlines the need for further investigations into the regulation of the immune system under physical stress.

\section{Acknowledgements}

This work has been supported by Bio-Strath ${ }^{\circledR}$ AG, Zurich, Switzerland. The authors thank S. Dätwiler, Y. Eichholzer, E. Frey, B. Grob, M. Hauri, T. Saurenmann, and R. Steinmann for their excellent technical assistance. We also thank Professor J. Fehr and Ms R. Rüegg for determining total and differential white blood cell counts.

\section{References}

1 Colgan, M., ed. Katch, F. Effects of multinutrient supplementation on athletic performance In: Sports, Health and Nutrition Human Kinetics Publications, Champaign, Illinois, USA, 1986, pp. 21-50

2 Keen, C.L., and Hackman, R.M. Trace elements in athletic performance In: Sports, Health and Nutrition Human Kinetics Publications, Champaign, Illinois, USA, 1986, pp. 51-65

3 Astrand, P.O. and Rodahl, K. Textbook of work physiology McGraw-Hill Book Co, 1986, New York

4 Van der Beek, E.J. Vitamins and endurance training: Food for running or faddish claims? Sports Med 1985, 2, 175-197

5 Wootton, S. Nutrition for Sport Facts on File Publications 1988, New York

6 Keul, J., Jacob, E., Berg, A., Dickhut, H.-H. and Lehmann, M. Zur Wirkung von Vitaminen und Eisen auf die Leistungs- und Erholungsfähigkeit des Menschen und die Sportanämie Leichtathletik 1988, 29, 1083-1086

7 Keul, J., Jacob, E., Berg, A., Dickhut, H.-H. and Lehmann, M. Zur Wirkung von Vitaminen und Eisen auf die Leistungs- und Erholungsfähigkeit des Menschen und die Sportanämie Leichtathletik 1988, 30, 1115-1118

8 Parr, R.B., Porter, M.A. and Hodgson, S.C. Nutrition knowledge and practice of coaches, trainers, and athletes Phys Sports Med 1984, 12, 127-138

9 Alhadeff, L., Gualteri, C.T., and Lipton, M. Toxic effects of water soluble vitamins Nutri Rev 1984, 42, 33-48

10 Blom, W., Van der Berg, G.B., Hijmans, J.G.M., Pezyrembel, H. Ferandes, J., Scholte, H.R. and Sanders-Woudstra, J.A.R. Neurologic action of megadoses of vitamins Bibl Nutr Dieta 1986, 38, 120-135

11 Chandra, R.K. Nutrition, immunity, and infection: present knowledge and future directions Lancet 1983, 1, 688-691

12 Good, R.A. and Lorenz, E. Nutrition, immunity, ageing, and cancer Nutr Rev 1988, 46, 62-67

13 Kulkarni, A.D., Fanslow, W.C., Drath, D.B., Rudolph, F.B. and Van Buren, C.T. Influence of dietary nucleotide restriction on bacterial sepsis and phagocytic cell function in mice Arch Surg 1986, 121, 169-172

14 Bagshaw, J.M. and Leslie, G.B. The effects of 3 food supplements on feeding and growth rate in the rat $L a b$ Anim 1974, 8, 189-197

15 Joller, P.W. Stärkung der Immunabwehr gegenüber bakteriellen Infektionen durch ein Hefepräparat Swissmed 1988, 10, 30-35

16 Leslie, G.B., Frasdilla, J.C., Salmon, G.K. and Sturman, G. Die Wirkung einer lebenslangen Behandlung mit einem Hefepräparat (Bio-Strath) auf Überlebensrate und Infektionsresistenz bei Mäusen Swissmed 1988, 10, 36-38

17 Fitzgerald, L. Exercise and the immune system Immunol Today 1988, 9, 337-339

18 Simon, H.B. The immunology of exercise JAMA 1984, 252, 2735-2738

19 Eskola, J., Ruuskanen, O., Soppi, E., Viljanen, M.K., Järvinen, M., Toivonen, $H$. and Kouvalainen, $K$. Effect of sport stress on lymphocyte transformation and antibody formation Clin Exp Immunol 1978, 32, 339-345

20 Gmünder, F.K., Lorenzi, G., Bechler, B., Joller, P., Müller, J., Ziegler, W.H. and Cogoli, A. Effect of long-term physical exercise on lymphocyte reactivity: 
Similarity to space flight reactions Aviat Space Environ Med 1988, 59, 146-151

21 Hanson, P.G. and Flaherty, D.K. Immunological responses to training in conditioned runners Clin Sci 1981, 225-228

22 Moorthy, A.V., and Zimmerman, S.W. Human leukocyte response to an endurance race Europ J Appl Physiol 1978, 38, 271-276

23 Green, R.L., Kaplan, S.S., Rabin, B.S., Stanitski, C.L. and Zdziarski, U. Immune function in marathon runners Ann. Allergy 1981, 2, 73-75

24 Keast, D., Cameron, K. and Morton, A.R. Exercise and the immune response Sports Med 1988, 5, 248-267

25 Roberts, J.A. Viral illnesses and sports performance Sports Med 1986, 3, 298-303

26 Besedowsky, H.O., Del Rey, A., Sorkin, E., Da Prada, M. and Keller, H.H. 1979 Immunoregulation mediated by the sympathetic nervous system Cell Immunol 1979, 48, 346-355

27 Dorian, B. and Garfinkel, P.E. Stress, immunity and illness - a review Psychol Med 1987, 17, 393-407

28 Lorenzi, G., Fuchs-Bislin, P., Cogoli, A. Effects of hypergravity on 'whole-blood' cultures of human lymphocytes Aviat Space Environ Med 1986, 67, 1131-1135

29 Wüthrich, B., Joller-Jemelka, H.I. and Grob, P.J. Investigations into the influence of mountain climate on humoral immune parameters in atopic dermatitis, psoriasis and controls Dermatologica 1988, 177, 177-260

30 Da Prada, M. and Zürcher, G. Simultaneous radioenzymatic determination of plasma and tissue adrenaline, noradrenaline and dopamine within the femtomole range Life Sci 1976, 10, 1161-1174

31 Davidson, R.J.L., Robertson, J.D., Galea, G. and Maughan, R.J. Hematological changes associated with marathon running Int J Sports Med 1987, 8, 19-25

32 Galbo, H. Hormonal and metabolic adaptation to exercise Thieme, New York 1983

33 Fritz-Niggli, H. Beeninflussung des Strahlensyndrome der weissen Maus durch Verfütterung eines Hefe-Präparates (Bio-Strath) Hippokrates 1967, 38, 812-814
34 Michel, C. and Fritz-Niggli, H. Die Beeinflussung der Fertilität der weissen Maus durch kleine Strahlenmengen und ein Hefepräparat (Bio-Strath) Radiol Clin Biol 1973, 42, 222-223

35 Ireson, J.D., Conway, G.E. and Schwarzenbach, F.H. The effect of a complex yeast preparation, as a food supplement, on the growth of Ehrlich's ascites tumour in mice Eur J Cancer 1972, 8, 159-166

36 Neumann, G., Schneeweiss, U. and Findeisen, D.G.R. Neuere immunologische Aspekte der Raumfahrtmedizin Med Sport 1986, 26, 231-237

37 Bosenberg, A.T., Brock-Utne, J.G., Gaffin, S.L., Wells, M.T., Blake, G.T. Strenuous exercise causes systemic endotoxemia J Appl Physiol 1988, 65, 106-108

38 Brock-Utne, J.G., Gaffin, S.L., Wells, M.T., Gathiram, P., Sohar, E., James, M.F., Morrell, D.F. and Norman, R.J. Endotoxaemia in exhausted runners after a long-distance race $S$ Afr Med J 1988, 73, 533-536

39 Lewicki, R., Tchorzeswki, H., Majewska, E., Nowak, Z. and Baj, Z. 'Effect of maximal physical exercise on T-lymphocyte subpopulations and on interleukin 1 (IL 1) and interleukin 2 (IL 2) production in vitro Int $J$ Sports Med 1988, 9, 114-117

40 Oshida, Y., Yamanouchi, K., Hayamizu, S. and Sato, Y. Effect of acute physical exercise on lymphocyte subpopulations in trained and untrained subjects Int $J$ of Sports Med 1988, 9, 137-140

41 Pedersen, B.K., Tvede, N., Hansen, F.R., Andersen, V., Bendix, T., Bendixen, G., Bendtzen, K., Galbo, H., Haar, P.M., Klarlund, K., Sylvest, J., Thomsen, B.S. and Halkjær-Kristensen, J. Modulation of natural killer cell activity in peripheral blood by physical exercise Scand J Immunol 1988, 27, 673-678

42 Ohno, H., Doi, R., Yamashia, K., Yamamura, K., Itoh, Y., Kawai, T. and Taniguchi, N. Effects of physical exercise on the concentrations of $\alpha-2$ microglobulin and $\beta-2$ microglobulin in human plasma J Sports Med 1985, 25, 65-68

43 Eberhardt, A. Influence of motor activity on some serologic mechanisms of nonspecific immunity of the organism Acta Physiol Pol 1971, 22, 185-194 